\title{
Vaikuttaako karsinan lattiamateriaali tai vasikoiden siirto niiden veren kortisoli- tai kasvuhormonipitoisuuksiin?
}

\author{
Laura Hänninen ${ }^{1)}$, Peter Løvendahl ${ }^{2}$, Anne Marie de Passillé ${ }^{3)}$ ja Jeffrey Rushen ${ }^{3)}$ \\ ${ }^{1)}$ Eläinten hyvinvoinnin tutkimuskeskus, PL 57, 00014 Helsingin Yliopisto \\ 2) Animal Breeding and Genetics, Research Centre Foulum, Po Box 57, DK-8830, Denmark \\ ${ }^{3)}$ Dairy and Swine Research and Development Centre, PO Box 90, QCJLM IZ3, Canada
}

\section{Johdanto}

Nautojen ja muiden kotieläinten stressiä mitattaessa on perinteisesti keskitytty kortisoliin ja sen tuotantoon vaikuttavien hormonien mittaukseen. Kasvuhormonin erittyminen on myös stressille altis. Kortisolin konsentraatio ja pulssien kesto vaikuttavat kuitenkin kasvuhormonin erittymiseen stressitilanteissa moni-ilmeisesti joko vähentäen tai lisäten kortisolin tuotantoa (Giustina and Veldhuis 1998).

Kortisolin ja kasvuhormonin mittaus ei ole kuitenkaan ongelmatonta, sillä molemmilla hormoneilla on vahva vuorokausirytmi sekä pulssimainen erittymistapa (Lefcourt et al. 1993, Lefcourt et al. 1995). Tämän vuoksi käytettäessä kasvuhormonin tai kortisolia stressireaktion mittarina, on näytteitä otettava tiheästi ympäri vuorokauden (Ladewig and Smidt 1989). Woolliams yms. (1993) mukaan perinteiset tilastolliset menetelmät eivät riittävästi tunnista pitkiä pulsseja.

Uni on yksi yhteisistä kasvuhormonin ja kortisolin tuotannon säätelytekijöistä ihmisillä ja laboratorioeläimillä (Giustina ja Veldhuis, 1998). Naudoilla unen ja kasvuhormonin tai kortisolin erittymisen yhteyttä ei ole vielä osoitettu. Kasvuhormonin ja kortisolin erittymiseen tiedetään aikuisilla naudoilla vaikuttavan kuitenkin samat tekijät, jotka muuttavat nautojen lepokäyttäytymistä: Lattian kovuus vähentää aikuisten nautojen lepoa (Haley et al., 2001) sekä lisää niiden kortisolin erittymistä (Ladewig and Smidt 1989). Kun lehmien makuullemeno estyy, niiden kasvuhormonin tuotanto vähenee (Munksgaard and Løvendahl, 1993). Ei kuitenkaan ole tutkimuksia lattiamateriaalin vaikutuksista nuorten vasikoiden kasvuhormonin tai kortisolin tuotantoon.

Nuoria vasikoita uudelleen ryhmitellään ja siirrellään kasvatusyksiköstä toiseen. Siirtojen otaksutaan olevan yksi tuotantovaiheen stressitekijöistä, joka voi muuttaa mm. uni- ja aktiivisuusrytmejä (mm. Veissier et al. 1989) ja oletamme sen vaikuttavan myös kortisoli- ja kasvuhormonin vuorokausirytmeihin.

Tässä tutkimuksessa tarkastelimme kasvuhormonin ja kortisolin pulssimaista erittymistapaa ja vuorokausirytmiä vasikoilla jotka olivat 8 viikon ajan kasvaneet joko kova- tai pehmeäalustaisessa yksilökarsinassa. Mahdollista siirron stressivaikutusta vasikoiden kasvuhormoni ja kortisolin erittymiseen tarkasteltiin siirtämällä puolet koevasikoista identtiseen, mutta eläimille vieraaseen kasvuympäristöön.

\footnotetext{
Aineisto ja menetelmät

Noin viikon ikäiset Holstein-rotuiset sonnivasikat (keskipaino $48 \pm 1.0 \mathrm{~kg}$ ) satunnaistettiin jompaankumpaan kahdesta yksilökarsinakäsittelystä 9 - 10 viikoksi: 12 vasikkaa karsinoihin, joissa oli betonilattia (BETONI) ja 12 vasikkaa karsinoihin, jossa oli betonilattian päällä $\mathrm{n} .5 \mathrm{~cm}$ paksu kumimatto (Cloud 9, NRI Industries, Kanada) (KUMIMATTO). Molemmat yksilökarsinatyypit olivat samankokoisia $(1.05 \mathrm{~m} * 1.8 \mathrm{~m})$ ja ne kuivitettiin päivittäin kahdella lapiollisella (n. $2 \mathrm{~kg}$ ) sahanpurua. Vasikoilla oli rajallinen näkö- ja kosketuskontakti naapurikarsinoiden vasikoihin metallitankoseinien läpi. Karsinatyypit oli satunnaistettu tasapuolisesti kahteen koehuoneeseen. Huoneissa oli mekaaninen ilmanvaihto ja keskilämpötila $+19 C^{0}$ (vaihteluväli $+14 C^{0}-+33 C^{0}$ ). Eläintiloissa oli valot päällä klo 6.00 18.00 ja yöaikaan antoivat valoa himmeät viiden luxin punaiset jouluvalot. Vasikoiden terveydentila ja rehunkulutus tarkastettiin päivittäin. Vasikat vieroitettiin juomarehusta 7 viikon ikäisinä, ja ne saivat sen jälkeen vapaasti vettä, väkirehua (klo 15.30) ja heinää (klo 6.00). Karsinat siivottiin klo 6.15 7.00 .

Vasikoiden verinäytteenotto- ja siirtokoe oli 10-11 elinviikon iässä. Vuorokausi ennen verinäytteiden ottoa vasikoille laitettiin kanyylit kaulalaskimoon. Verinäytteet ja siirtotestit tehtiin kahdessa erässä viikon välein (kts. kuva 1). Vasikoilta otettiin ensimmäisen vuorokauden ajan verinäytteitä 20 minuutin välein perustason selvittämiseksi. Verinäytteen ottoa jatkettiin kaikista eläimistä myös siirron jälkeen seuraavat 24 tuntia.
} 
1. toisto

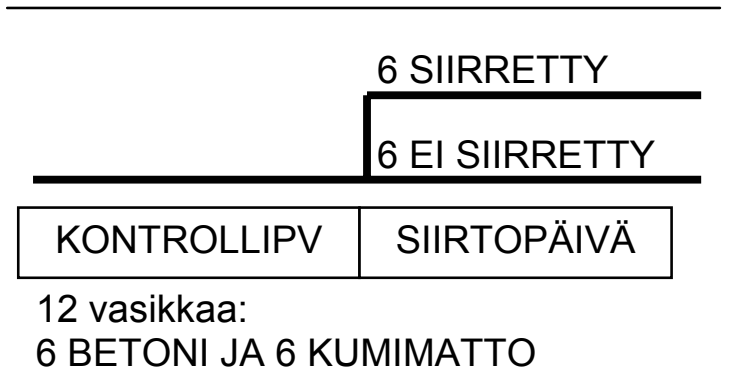

2. toisto

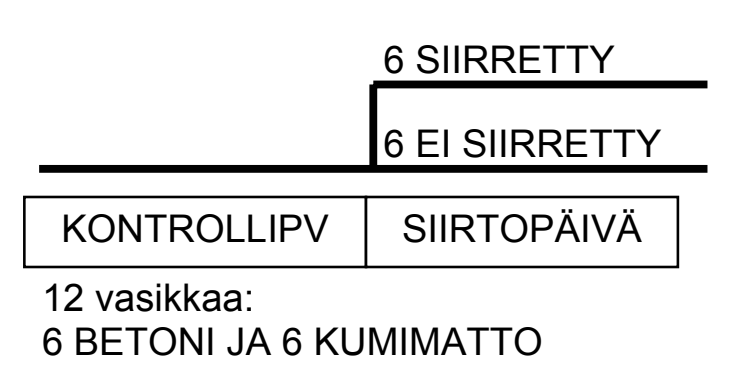

Kuva 1. Koeasetelma. BETONI: yksilökarsina, jossa purukuivitettu betonipohja, KUMIMATTO: yksilökarsina, jossa betonin päällä $5 \mathrm{~cm}$ paksu purukuivitettu kumimatto. Molempien mitat $1.8 * 1.05 \mathrm{~m}$.

Plasman kasvuhormonipitoisuus määritettiin kaksoisvasta-aine RIA:lla (Peticlerc et al. 1987) ja kortisolipitoisuudet kaupallisella ELISA-kitillä (No. \#402210, Neogen corp.). Kummankin analyysin herkkyys oli $1 \mathrm{ng} / \mathrm{ml}$.

Tilastollista tarkastelua varten plasman kasvuhormoni ja kortisolipitoisuudet log-korjattiin normaalia jakaumaa mukaileviksi. Takaisinkorjattuja arvoja $\left(\mathrm{e}^{\mathrm{x}}\right)$ käytetään taulukoissa ja kuvaajissa. Kasvuhormoni- ja kortisolipulssit määritettiin tilastollisesti plasman konsentraatioiden vaihteluista. Yksi pulssi voi sisältää useampia 20 minuutin välein otettuja näytteitä. Lyhyesti, kyseinen tilastollinen metodi määrittää pulssiksi ne konsentraatioiden nousut, jotka ylittävät tietyn kynnysarvon. Yksityiskohtaisempi selvitys aiheesta on saatavilla mm. (Woolliams et al. 1993) ja Breierin yms. (1986) artikkeleista.

Pulsseista määritettiin tilastollisesti useita pulssimääreitä, kuten pulssien lukumäärä, pulssien välinen aika ja pulssin leveyttä kuvaava suure; keskiarvo kahden perättäisen ylimmän pulssipisteen välillä (YLÄLEVEYS). Lisäksi vuorokaudenaika jaettiin analyysiä varten kahden tunnin jaksoihin. Split-splot sekamallien avulla testattiin eläinten siirron sekä lattiatyypin vaikutusta plasman kortisolija kasvuhormonin konsentraatioihin sekä pulssiparametreihin. Lopullisessa mallissa oli plasman konsetraatioita analysoitaessa kiinteinä vaikutuksina Lattiatyyppi (BETONI vs. KUMIMATTO), Siirtovaikutus (SIIRRETTY vs. EI SIIRRETTY), Päivä (KONTROLLIPV vs. SIIRTOPV), Vuorokaudenaika ja Toisto. Yhdysvaikutukset analysoitiin Lattiatypin, Päivän ja Siirtovaikutuksen välillä. Satunnaisvaikutuksina oli vasikka pesitettynä Siirtovaikutukseen, Toistoon ja Lattiatyyppiin. Pulssisuureet analysoitiin vastaavalla mallilla, mutta malllissa oli mukana myös pulssien välinen aika.

\section{Tulokset ja niiden tarkastelu}

Nuorilla vasikoilla oli keskimäärin 5-6 kortisolipulssia vuorokaudessa, joka on vähemmän kuin aikuisilla naudoilla (Lefcourt yms. 1993). Keskimääräinen kortisolikonsetraatio vaihteli välillä 1-6 ng/ml, mikä vastaa vasikoilla mitattuja pitoisuuksia muissa tutkimuksissa (Wohlt et al. 1994). Kortisolipitoi-

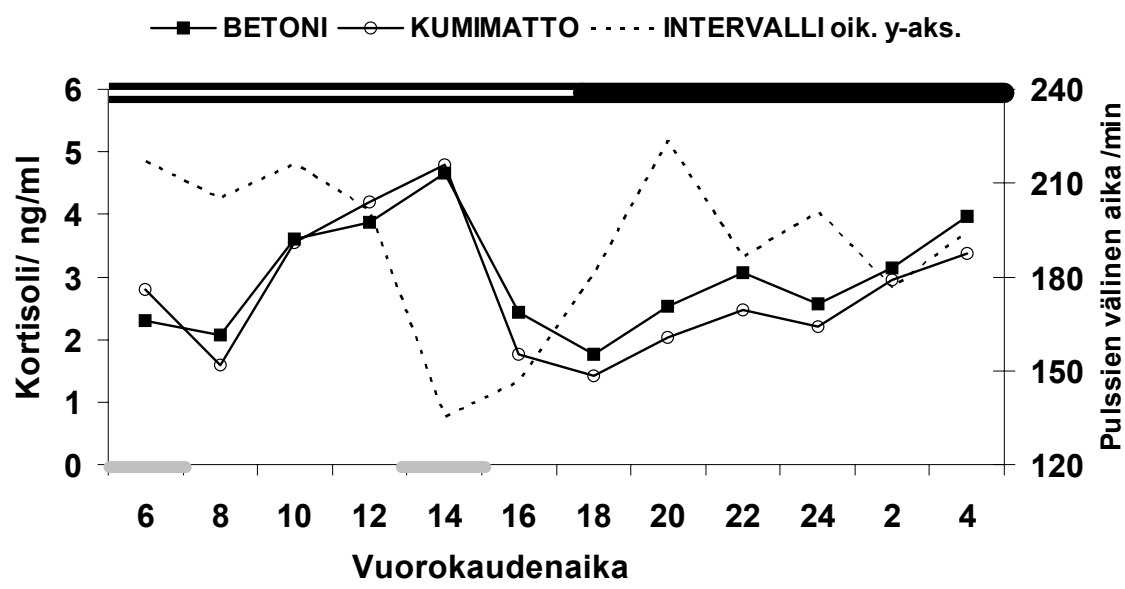
suus vaihteli vuorokaudenajan mukaan, ja oli korkeimmillaan keskipäivällä (kts. kuva 2). Vanhemmat tutkimukset aikuisilla naudoilla ovat löytäneet ristiriitaisia tuloksia kortisolin vuorokausirytmistä (Fulkerson and Tang 1979, Fulkerson et al. 1980), (Thun et al. 1981). Syinä näiden tutkimusten keskinäisiin eroa- 
vaisuuksiin saattavat olla kokeiden pienet eläinmäärät sekä erilaiset tilastolliset metodit. Tutkimuksemme vasikat olivat noin kahden kuukauden ikäisiä, joten niiden vuorokausirytmi ei ollut vielä välttämättä täysin kehittynyt

aikuisen kaltaiseksi. Vauvoilla (Mantagos et al. ) ja porsailla (Ruis et al. 1997) rytmi kehittyy vasta 36 kuukauden ikäisenä. Ihmisistä ja jyrsijöillä kortisoli on korkealla heti valveillaolojakson alussa, ja sitä pidetään merkkinä biologisen vuorokauden alkamisesta (Czeisler and Klerman 1999). Kortisolipulssien välinen aika lyheni väkirehuruokinnan aikaan, joka on yhtäpitävä mm. (Follenius et al. 1982) tutkimusten kanssa.

Vasikoilla oli keskimäärin 4-5 kasvuhormonipulssia vuorokaudessa ja pitoisuudet olivat välillä

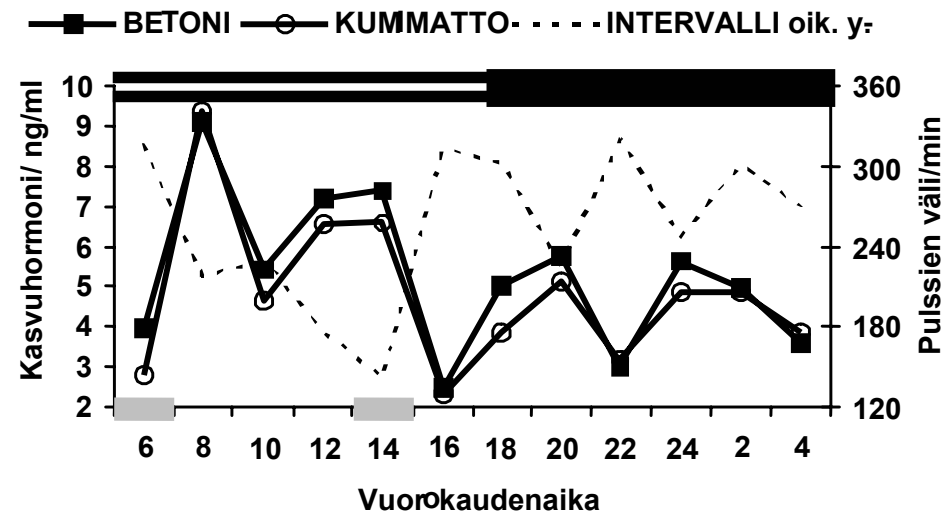

2-10 ng/ml, kuten myös aiemmissa tutkimuksissa on näytetty (Breier et al. 1986, Lefcourt et al. 1993). Päiväsaikaan kasvuhormonin konsentraatiot olivat korkeampia ja myös pulssien väli lyheni (kts. kuva 3.).

Laboratorio-

eläimillä ja jyrsijöillä kasvuhormonia vapauttavan hormonin (GHRH) eritys on voimakkaasti kytköksissä uneen (Giustina ja Veldhuis, 1998). Myös lampailta on viitteitä, että niiden kasvuhormonin ja levon välillä olisi yhteyttä (Laurentie et al. 1989). Vastaavaa yhteyttä ei ole näytetty vielä naudoilla toteen, mutta naudat nukkuvat lyhyissä jaksoissa ympäri vuorokauden (Ruckebusch 1974), joten kasvuhormonin rytminen eritys ei sulje ko. yhteyttä pois.

Vasikoiden siirto ei vaikuttanut tilastollisesti niiden kortisoli- tai kasvuhormonin konsentraatioihin. Tähän saattaa vaikuttaa eläinten siirtotapa, me siirsimme yhden vasikan kerrallaan, rauhallisesti

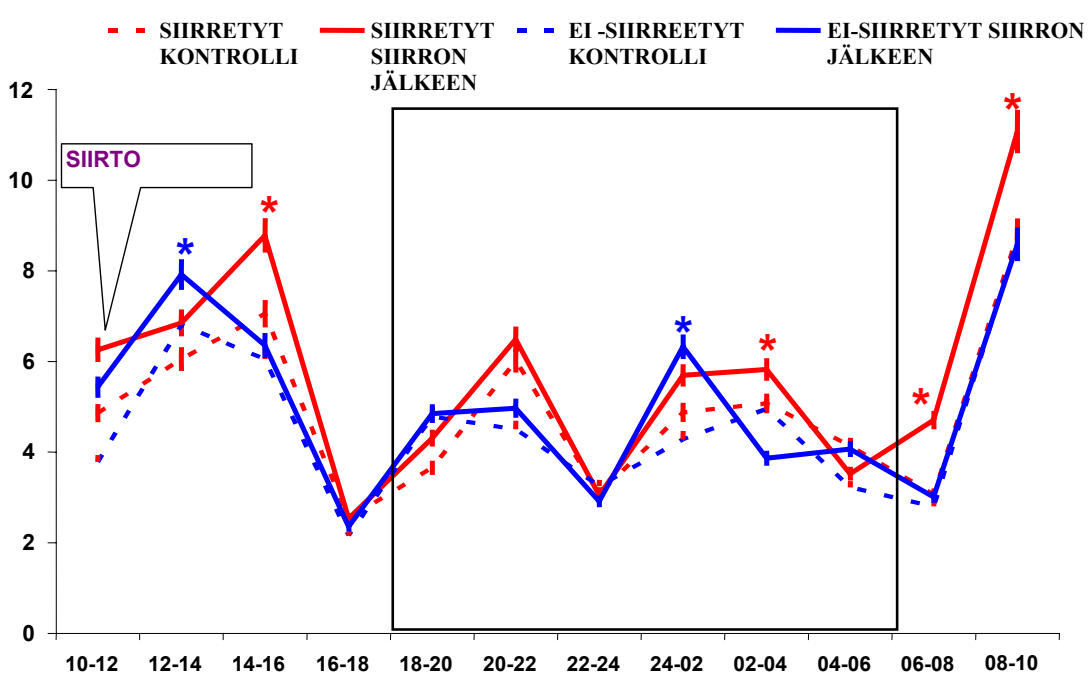
huutamatta tai läimäyttämättä eläimiä. Lisäksi, pysyivät hoitajat, hoitorutiinit ja yksi naapurivasikka siirretyille eläimille samana myös uudessa kasvatustilassa Siirto sen sijaan muutti vasikoiden kasvuhormonin erittymisrytmiä (kts. kuva 4), joka saattaa heijastaa niiden lisääntynyttä fyysistä aktiviteettia ja/tai uni-valverytmin muutoksia (Giustina ja Veldhuis 1998 ).

BETONI ja KUMIMATTO vasikoiden välillä ei ollut eroa vuorokauden keskimääräisessä kortisoli- tai kasvuhormonipitoisuuksissa: 2.9 [2.6- 3.3] ng/ml vs. 2.6 [2.3 - 2.9$] \mathrm{ng} / \mathrm{ml}$ tai 5.0 [4.3 - 5.8] vs. 4.5 [ $3.9-5.2] \mathrm{ng} / \mathrm{ml}$. Vuorokauden ajan ja lattiatyypin välillä oli kuitenkin tilastollisesti merkitsevä yhdysvaikutus kummallakin hormonille $(\mathrm{p}<0.001)$ : BETONI vasikoilla oli korkeampi kortisolikonsetraatio alkuillasta kuin KUMIMATTO vasikoilla (kts. kuva 1.). Vastaavaa trendiä mukailee myös kasvuhormonikonsentraatio (kuva 2.). Sen sijaan BETONI vasikoiden kasvuhormonipulssit olivat KUMIMATTO vasikoita korkeampia $(16.1[12.8-20.4] \mathrm{ng} / \mathrm{ml}$ vs. $11.3[9.0-14.1] \mathrm{ng} / \mathrm{ml}) \mathrm{ja}$ pulssien väli oli suuntaa antavasti pitempi (272 [232 - 318] min vs. 225 [195 - 260] min). Emme voi sanoa, johtuiko vuorokausivaihtelu eri lattiatyyppien välillä kahden kuukauden kasvatusoloista vai 
